\title{
THE PATHOGENESIS OF CYSTINURIA. I. CHROMATOGRAPHIC AND MICROBIOLOGICAL STUDIES OF THE METABOLISM OF SULPHUR-CONTAINING AMINO-ACIDS
}

\author{
By C. E. DENT, J. G. HEATHCOTE, 1 AND G. E. JORON 2 \\ (From the Medical Unit, University College Hospital Medical School, London, and Research \\ Association of British Flour-Millers, St. Albans, England)
}

(Submitted for publication March 16, 1954 ; accepted May 14, 1954)

Recent studies of cystinuria from this laboratory (1) have suggested that the disease does not, as had been assumed by most previous workers, involve an innate inability to metabolize one or other of the sulphur-containing amino-acids. On the contrary the defect responsible for the life-long constant excretion of large amounts of cystine appears to be due to a peculiarity only of renal function, that is, to a "low renal threshold" for cystine presumably due to diminished tubular reabsorption. This view was based in the first instance on the finding of large quantities of lysine, arginine, and perhaps ornithine, in the urine, a fact not readily explainable by Garrod's simple concept of an "inborn error of metabolism" of cystine, but quite consistent with the findings in certain other renal amino-acidurias. It was further supported by preliminary chromatographic and microbiological determinations of plasma cystine levels, since they were found to be no higher in cystinuric subjects than in normal subjects. This has since been confirmed by polarographic determinations (2). The renal theory had already been suggested by other workers but had only been subjected to one earlier incomplete investigation, which appears to have been largely overlooked (3).

Although the renal theory explains readily all of the spontaneously occurring clinical and biochemical phenomena it is still difficult to fit into it much of the work of others in which the metabolism of sulphur-containing amino-acids had been investigated (4). This work is often contradictory and suffers greatly from the inadequacy of the methods of analysis then available. The weight of evidence however indicated that cystine given by mouth to a cystinuric subject did not result in an

\footnotetext{
1 Now at Distillers Company (Biochemicals) Ltd., Speke, Liverpool.

2 Nuffield Dominion Travelling Fellow. Now at Montreal General Hospital, Montreal, Canada.
}

increased excretion of cystine. Methionine and cysteine on the other hand did increase the cystine output. This had been interpreted as an error of metabolism not of cystine, but of cysteine, methionine acting only as a source of cysteine (4).

In the present paper we report fuller investigations on the changes in plasma and urine aminoacids in two normal patients and two cystinuric patients after feeding loading doses of cystine, cysteine, and methionine. Only acute experiments on fasting subjects were carried out as this technique should exaggerate the metabolic changes more than the experiments done by others on the basis of 24-hour urine collections. Paper chromatography was chosen as the chief method of analysis owing primarily to its high specificity but also because of its ability to indicate changes in concentration of every amino-acid present in appreciable quantity, the importance of doing which having already been stressed (5). Owing to the only semi-quantitative nature, however, of paper chromatography, microbiological assays for cystine were also carried out in most of the experiments. As this quantitative method is also subject to question, especially in the case of cystine, the present report was held up until a more extensive check had been carried out by polarography (6).

\section{METHODS USED AND CASES STUDIED}

Cases. The experiments were performed on two normal subjects (G. J. and D. F.) and on two cystinuric subjects (L. L. and J. H.). G. J. was a male age 33, weight $81.8 \mathrm{Kg}$., D. F., a female age 23 , weight $52.3 \mathrm{Kg}$. The cystinuric subjects (under the same initials) are described in a little more detail by Dent and Rose (1). Briefly, L. L. was a taxi driver aged 41 (weight $73 \mathrm{Kg}$.) who had had attacks of renal colic since 17 years of age, and had occasionally passed small smooth greyish white stones proved on analysis to be of cystine. X-ray showed a small opacity to be present in the left renal area. J. H. was a fitter aged 23 (weight $68 \mathrm{Kg}$.) who had had three attacks of renal colic at 11,19 , and 22 years of age. There 
was no X-ray evidence of stones. His urine usually deposited typical cystine crystals on standing. The urine of both cystinuric subjects gave the typical cystine-lysine-arginine pattern on chromatographic analysis.

Procedure during experiment. The subjects were fed separately each of the three amino-acids, at least two days intervening between each test. The quantities taken were equivalent in respect of their sulphur content, i.e., $5 \mathrm{~g}$. of L-cystine, $6.2 \mathrm{~g}$. of DL-methionine and $6.5 \mathrm{~g}$. of L-cysteine hydrochloride. The latter was neutralized with $\mathrm{NaOH}$ to $\mathrm{pH} 7.0$ immediately before ingestion. The subjects ate nothing from the previous evening and until the experiment was over. They were kept lying on a couch throughout the test in order to minimize the changes in glomerular filtration rate known to occur with changes in posture and activity. At the beginning of test ( 0 hour) the amino-acid was drunk either dissolved or suspended in water, and a liberal water intake was maintained subsequently to ensure adequate urine flow and bladder emptying. Blood samples were obtained immediately before the amino-acid was taken and again at 1/2,1,2, 4, and 6 hour intervals. The blood was taken into a heparinized syringe, immediately centrifuged and the plasma separated and stored at $4^{\circ}$. Specimens were rejected if any trace of hemolysis was present. The urine specimens were collected at $0,1,3,5$, and 7 hours. The last time of emptying the bladder before the experiment was also noted so that the specimen collected at 0 hour could also be timed. All the urines were preserved with thymol at $4^{\circ}$.

The normal subject, D. F., felt nauseated shortly after swallowing the cysteine and vomited shortly before the 1 hour blood sample was taken.

Chromatographic analyses. The plasma samples were prepared for analysis by, first, ultrafiltration to remove the proteins, the method used being that described by Dent and Schilling (7), secondly, by electrolytic desalting, using a micromodification (8) of the ingenious apparatus devised by Consden, Gordon, and Martin (9). The urine samples were run without any pretreatment, the volume taken for each analysis being that passed in a given time interval, usually $2 \mathrm{sec}$. or $2 / 5 \mathrm{sec}$.

Two-way paper chromatograms ( 18 by 22 inches) were used exclusively for the amino-acid analyses. Phenol/ $\mathrm{NH}_{3}$ and collidine-lutidine/ $\mathrm{Et}_{2} \mathrm{NH}$ were the two solvents used (10). Each sample of desalted plasma ultra-filtrate (625 $\mu 1$.$) was run alone and again after oxidation with$ $10 \mu \mathrm{l} . \mathrm{H}_{2} \mathrm{O}_{2}$ (30 per cent) and $10 \mu 1.0 .1$ per cent ammonium molybdate so as to enable methionine and cystine (and/or cysteine) to be detected in the form of methionine sulphone and cysteic acid, respectively (11).

Each set of 5 to 6 samples of urine or of desalted ultrafiltered plasma from one experiment was run simultaneously in the chromatogram cabinet. The resulting chromatograms were strictly comparable with each other and on being laid out side by side a most accurate picture of the changes taking place in plasma amino-acid levels and urine outputs could be obtained by merely comparing in turn the strengths and sizes of each amino-acid spot as it appeared in successive chromatograms. In order to determine approximately the plasma cystine (and/or cysteine) concentration a known but varying quantity of cysteic acid was placed on each chromatogram about 4 $\mathrm{cm}$. from the site of the plasma or urine sample. The quantities chosen covered the full range of cystine levels anticipated in the samples and were as far as possible placed on chromatograms likely to contain similar amounts in the sample. In this way each cysteic acid spot obtained from the oxidized cystine in the sample could be matched by eye with a similar strength spot on the same chromatogram or on one of the others in the same batch, and a semi-quantitative estimate obtained. This method was considered to be very accurate when used for determining relative strengths of an aminoacid in a series of samples from one experiment, and we were impressed by the definiteness of the serial changes shown as varying strengths of the spot on the chromatograms in, say, the cystine levels of plasma after feeding cysteine (see later). However, a fairly constant loss of cystine always occurs during the $\mathrm{H}_{2} \mathrm{O}_{2}$ oxidation so we expected the absolute values to be on the low side.

As a further check, each urine sample was tested directly under standard conditions, for cystine and for cysteine by the cyanide/nitro-prusside test (12).

Microbiological assays. Plasma samples were first prepared for assay as previously. described for chromatographic analysis, except that the electrolytic desalting was not carried out since preliminary experiments showed that the small amounts of mercury introduced into the samples proved to be toxic to the assay organism. After ultrafiltration, each plasma sample was diluted, where necessary, with distilled water to the appropriate volume before assay for cystine at 2 to 4 levels in duplicate whereever possible.

The cystine assays were carried out using Leuconostoc mesenteroides P-60 since, according to Riesen, Spengler, Robblee, Hankes, and Elvehjem (13), this organism is the most specific in its response to cystine as distinct from its simple derivatives, and the standard curves are more reproducible than those obtained with any other strain of bacteria. The most suitable medium was found to be an oxidized peptone medium which was essentially that described by Lyman, Moseley, Wood, and Hale (14) with minor modifications chiefly in respect of the mineral and vitamin concentrations.

Urine samples were diluted from $1: 25$ to $1: 500$ (by vol.) depending on the concentration of cystine in the urine. In some samples containing very high concentrations, crystallization of the cystine had taken place before they were received for assay, and in such cases, careful homogenization was necessary to ensure reproducible results. The diluted urine samples were assayed in duplicate at 3 to 5 levels.

The microbiological assay of the true free cystine in urine normally presents considerable difficulty owing to the presence of many diverse substances stimulating to the growth of the organism. The problem was overcome in the present experiments in the following manner: A solution was made by dissolving Difco peptone $(50 \mathrm{~g}$.) in 
TABLE I

Cystine in plasma and urine after $5.0 \mathrm{~g}$. of l-cystine (microbiological assay)

\begin{tabular}{|c|c|c|c|c|c|c|c|c|c|c|c|}
\hline & Time $(k r)$. & $-\frac{1}{1}$ & o & 1 & 1 & 2 & 3 & 4 & 5 & 6 & 7 \\
\hline D.F. (normal) & $\begin{array}{l}\text { Plasma }(\mu g . / m l .) \\
\text { Urine }(\mu g . / \min .)\end{array}$ & & $\leftarrow \begin{array}{l}11 \\
-37 \leftarrow\end{array}$ & $12 \rightarrow$ & - & $\leftarrow \begin{array}{c}9 \\
58\end{array} \rightarrow$ & & $\leftarrow \overline{48} \rightarrow$ & & $\leftarrow \overline{44} \rightarrow$ & \\
\hline J. H. (cystinuric) & $\begin{array}{l}\text { Plasma }(\mu g . / m l .) \\
\text { Urine }(\mu g . / \min .)\end{array}$ & & $\leftarrow 585$ & $\begin{array}{c}13 \\
838\end{array} \rightarrow$ & 12 & 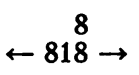 & & $\leftarrow \begin{array}{c}10 \\
\leftarrow 630 \rightarrow\end{array}$ & & $\leftarrow 788 \rightarrow$ & \\
\hline L. L. (cystinuric) & $\begin{array}{l}\text { Plasma }(\mu g . / m l .) \\
\text { Urine }(\mu g . / \min .)\end{array}$ & & $\begin{array}{c}9 \\
\leftarrow 558 \leftarrow\end{array}$ & $\overline{558} \rightarrow$ & 10 & $\leftarrow \begin{array}{r}11 \\
\leftarrow 588\end{array} \rightarrow$ & & $\leftarrow 653 \rightarrow$ & & $\leftarrow \overline{465} \rightarrow$ & \\
\hline
\end{tabular}

a mixture of urine $(90 \mathrm{ml}$.$) , water (360 \mathrm{ml}$.$) and con-$ centrated $\mathrm{HCl}(50 \mathrm{ml}$.$) . To this solution, hydrogen$ peroxide ( $15 \mathrm{ml}$. of 100 vols.) was added and the whole was allowed to stand overnight. The mixture was then treated in the usual manner as described by Lyman, Moseley, Wood, and Hale (14) and diluted to one liter. The requisite salts, essential vitamins, methionine, tyrosine, and tryptophan were added to $400 \mathrm{ml}$. of this solution to make one liter, of double strength medium. The assay was carried out in the same manner and using the same organism as for the plasma assays. The sensitivity of the organism to cystine was increased considerably in this unusual medium and the assay was much improved. In addition, wherever possible, in the making up of the peptone-urine medium, the urine from the particular subject under investigation, whether control subject or cystinuric subject, was used. For this purpose, a separate, bulked, 24-hour sample of urine was collected before the feeding experiments were carried out.

Despite the precautions taken, the assays of both plasma and urine samples still left something to be desired, partly no doubt due to the presence of peptides in the former samples and partly due to the peculiar assay difficulties in the case of cystine referred to previously by one

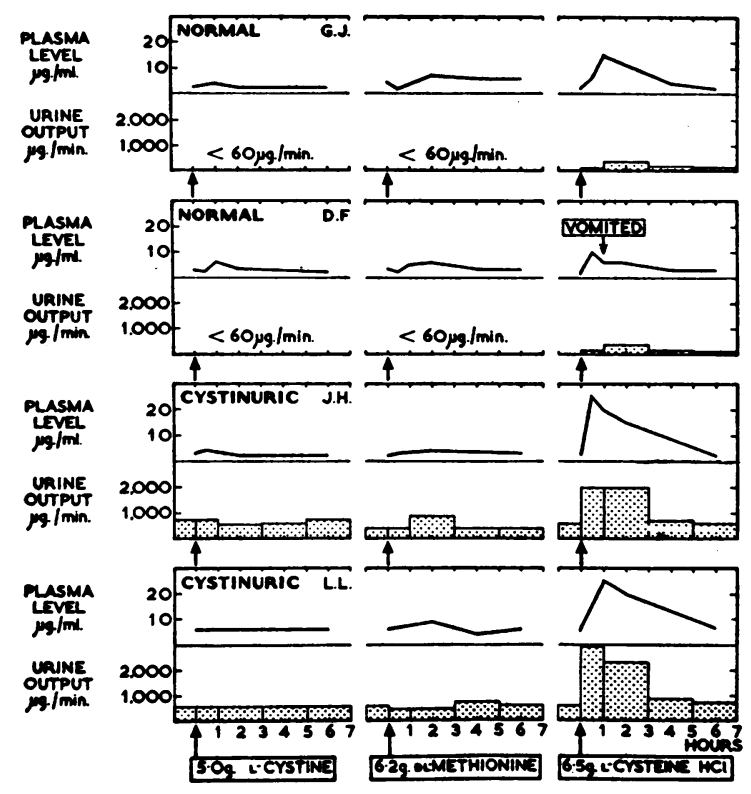

FIG. 1. of us (15). Furthermore, when the present work was carried out, the improved procedure of Camien and Dunn (16) had not been published and it would seem likely, therefore, in view of these authors' results, that the present microbiological assay results for both plasma and urine are relatively high. Nevertheless the results were reproducible and the general trends reliable.

\section{RESULTS}

\section{Chromatographic assays}

The relative changes in plasma level and urinary output of cystine following the ingestion of the three amino-acids can be seen from the graphs in Figure 1.

These changes and those in plasma levels of other amino-acids were as follows:

(a) In no subject was the plasma cystine appreciably raised after giving the cystine. Following its ingestion there was a slight increase in $\alpha$-amino-n-butyric acid level in the earlier samples from the normal subject, D. F. The cystinuric subject, J. H., showed a slightly higher than normal concentration of $\alpha$-amino-n-butyric acid in all specimens obtained in the fasting state and following the ingestion of cystine there was a further slight increase in $\alpha$-amino-n-butyric acid and methionine which was maximal at 1 hour. These changes were not reflected in the urine outputs.

(b) Following the ingestion of methionine the plasma cystine level showed no consistent changes, but the methionine rose to a high level maximal at 1 to 2 hours, and remained still appreciably raised after 6 hours. The normal subjects and cystinuric subjects behaved similarly and in all cases there was also a definite slight rise in $\alpha$-amino-n-butyric acid level which was usually maximal in the 6 -hour specimen. The urine output of methionine was greatly increased in all specimens passed while the plasma level was raised.

(c) Following the ingestion of cysteine there were in all cases large rises in plasma cystine levels. 
TABLE II

Cystine in plasma and urine after $6.2 \mathrm{~g}$. of dl-methionine (microbiological assay)

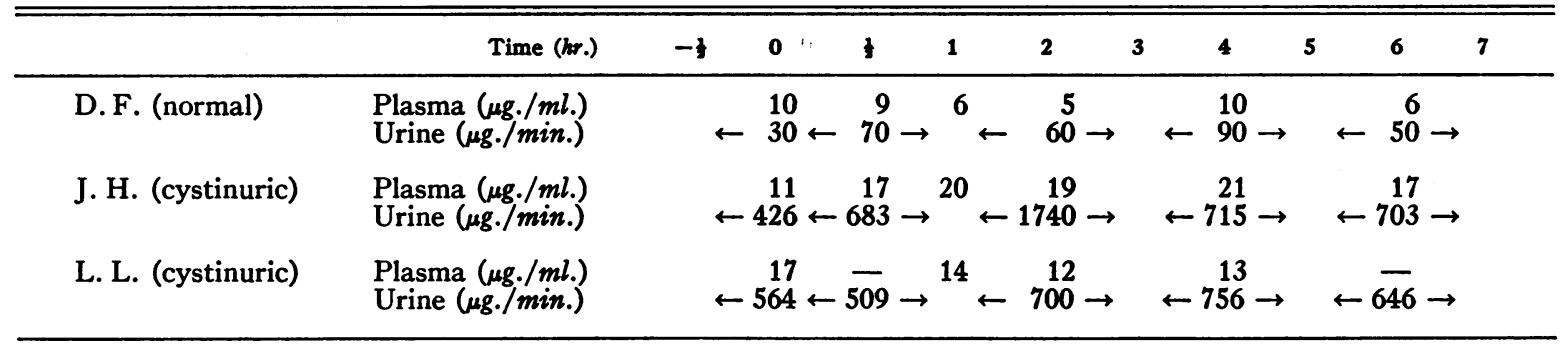

The only other change of note was in the cystinuric subject, J. H., who (as after taking cystine) showed a slight rise in $\alpha$-amino-n-butyric acid level.

An important negative finding was the absence of any detectable changes, in any of the experiments, in the plasma level or urinary output of lysine and of arginine.

Twenty-four hour samples of urine of the cystinuric subjects J. H. and L. L. were collected while they were on the ordinary hospital diet. Chromatographic analysis of the cystine output gave in both cases figures of the order of 800 to $900 \mathrm{mg}$. per 24 hour.

The cyanide/nitro-prusside testing of all the urines gave colour reactions for the cystine which corresponded approximately to the concentrations expected on the basis of the chromatographic assay. The nitro-prusside test also showed that traces of cysteine were present in some of the urines passed at the time when the maximal additional cystinuria was taking place after ingesting cysteine. At other times the urinary amino-acid appeared to be entirely cystine and not cysteine.

\section{Microbiological assays}

The results are shown in Figure 2 and Tables I-III. These confirm the main chromatographic findings as regards the changes in plasma cystine level and urine output (see above).

\section{DISCUSSION}

After ingesting a large dose ( $5 \mathrm{~g}$.) of cystine, only slight changes in plasma cystine level occurred. This confirms Hier (17), who used microbiological assays, and Brown and Lewis (3), who used a chemical method. We also confirmed that no increased cystine output occurred in either normal or cystinuric subjects. After methionine, the results were more ambiguous. The plasma cystine levels probably rose slightly and this was definitely followed in the cystinuric patients by an increased cystine output although the change in the normals, if any indeed occurred, was too small to be detectable. Spectacular changes however occurred after feeding cysteine. In all four subjects the plasma cystine level rose considerably and was associated with an increased urinary output. We appear, therefore, to have a ready explanation of the results of the metabolic experiments done by earlier workers, namely, the cystine output in the urine in any given subject is dependent mainly, at least, on the plasma cystine level, and the extent of cystine output at a given plasma level depends on whether the patient is cystinuric or otherwise, as the cystinuric patients always leak out into their

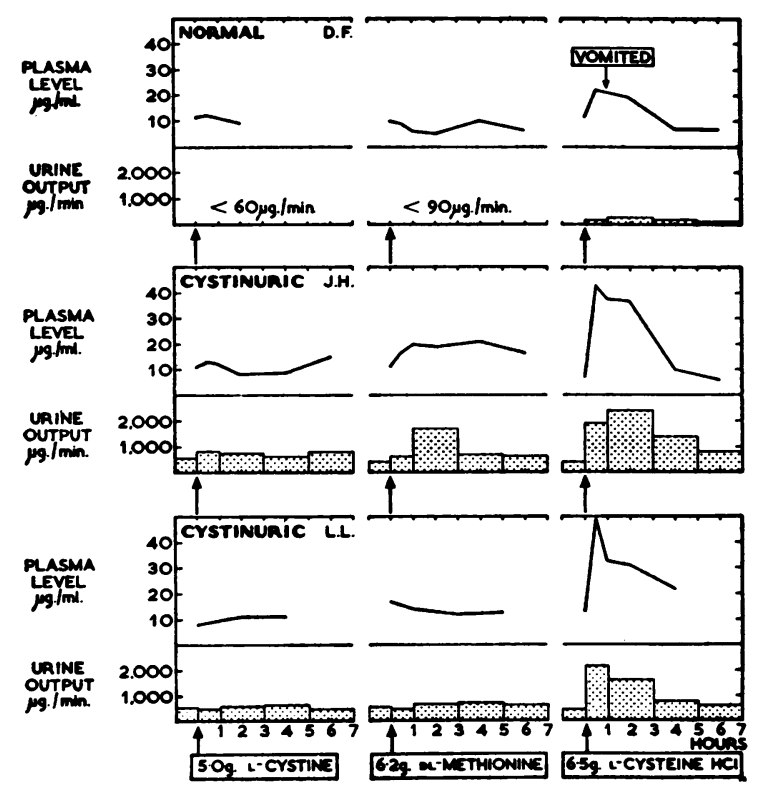

FIG. 2. 
TABLE III

Cystine in plasma and urine after $6.5 \mathrm{~g}$. of Lcysteine $\mathrm{HCl}$ (microbiological assay)

\begin{tabular}{|c|c|c|c|c|c|c|c|c|c|c|c|}
\hline & Time (hr.) & -1 & o & 3 & 1 & 2 & 3 & 4 & 5 & 6 & 7 \\
\hline D. F. (normal) & $\begin{array}{l}\text { Plasma }(\mu g . / m l .) \\
\text { Urine }(\mu g . / \min .)\end{array}$ & & 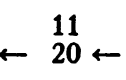 & $\begin{array}{r}22 \\
140\end{array} \rightarrow$ & - & $\leftarrow 230 \rightarrow$ & & $\begin{array}{c}7 \\
-140 \rightarrow\end{array}$ & & $\leftarrow \begin{array}{c}7 \\
60\end{array} \rightarrow$ & \\
\hline J. H. (cystinuric) & $\begin{array}{l}\text { Plasma (ug./ml.) } \\
\text { Urine }\left(\mu g_{.} / \min .\right)\end{array}$ & & $\leftarrow 463 \leftarrow$ & $\begin{array}{r}43 \\
1905 \rightarrow\end{array}$ & 38 & $\begin{array}{c}37 \\
\leftarrow 2489 \rightarrow\end{array}$ & & $\begin{array}{r}10 \\
-1465 \rightarrow\end{array}$ & & $\leftarrow 857^{6} \rightarrow$ & \\
\hline L. L. (cystinuric) & $\begin{array}{l}\text { Plasma }\left(\mu g_{.} / m l_{.}\right) \\
\text {Urine }\left(\mu g_{.} / \min .\right)\end{array}$ & & $\leftarrow \begin{array}{c}13 \\
\leftarrow 79 \leftarrow\end{array}$ & $\begin{array}{r}48 \\
2158\end{array} \rightarrow$ & 33 & $\begin{array}{r}31 \\
\leftarrow 1697 \rightarrow\end{array}$ & & $\begin{array}{r}22 \\
-\quad 780 \rightarrow\end{array}$ & & $\leftarrow \overline{612} \rightarrow$ & \\
\hline
\end{tabular}

urine more cystine than the normal subjects at all plasma cystine levels. This finding supports the "low renal threshold" theory of Dent and Rose (1) and is strong evidence against the "error of metabolism" theory of Garrod (18) and others. The equally rapid fall in the high plasma cystine levels shown by both normal and cystinuric subjects after taking cysteine is an important piece of evidence against the latter theory. If a true "error of metabolism" were present a "diabetic" type of cystine tolerance curve would have been expected in the cystinuric subjects.

Our results however still leave some puzzling features inadequately explained. Why does the plasma cystine level rise so much more after giving cysteine than after cystine? Brand, Cahill, and Harris (4) sought to explain the results of their metabolic experiments (in which the urine only was examined) by postulating that there were different metabolic pathways for cystine and cysteine and that it was only the metabolism of the cysteine (which was chiefly derived from methionine) that was disturbed in cystinuric subjects. We find this suggestion difficult to accept in view of the ready interconvertibility that must exist in the body between $-\mathrm{S}-\mathrm{S}-$ and $-\mathrm{SH}$ groups whether in the form of free amino-acids, peptides, such as glutathione, or whole proteins. Moreover in our results we have found no essential differences between the way normal and cystinuric subjects metabolize these amino-acids. Our tentative hypothesis is, therefore, that the differences in plasma levels may be due to different rates of absorption from the gut. Cysteine being readily soluble in water is very rapidly absorbed through the intestinal mucous membrane, probably all within the first hour, and it therefore reaches the portal blood in such a high concentration as temporarily to saturate the mechanisms for maintain- ing a constant blood level of cystine. The large dose of cystine on the other hand remaining almost entirely undissolved in the intestinal fluids is only taken into the portal blood relatively slowly and so is adequately dealt with by the liver and never reaches the systemic blood in appreciably raised concentrations. Another possibility is that the cystine is partly decomposed, say, into $\mathrm{H}_{2} \mathrm{~S}$ and alanine, by bacteria while in the gut, so preventing some from being absorbed at all. Our experiments with cystine were sufficiently prolonged for maximal absorption since earlier work on the increased urinary sulphur output in the urine after giving cystine by mouth has shown that the cystine must have been largely absorbed in some form or other in the 6-hour space of our experiment.

It has been repeatedly found in rats (Dent and Harbury, Unpublished work) that a similar cystinuria can be induced by feeding a single large dose of cysteine but not by the same dose of cystine. So, whatever the explanation, we are convinced that this is a general phenomenon which is not confined to cystinuric subjects. We can only find one reference in the literature to the feeding of cysteine to normal humans namely, Hess and Sullivan (19) who gave $2.6 \mathrm{~g}$. of the hydrochloride but reported no increased output of cystine in the 24-hour urine. Our present results do not confirm this and provide evidence that there is probably no clear-cut difference between the metabolism of cysteine by normal and cystinuric subjects. Increased cystine output after cysteine feeding cannot therefore be used as a diagnostic test for cystinuria (Freudenberg [20]).

\section{SUMMARY}

1. Chromatographic analyses of plasma and urine have been carried out during the 6 hours following the ingestion of large single doses of cys- 
tine, cysteine, and methionine by two normal and two cystinuric subjects. Most of the samples were also assayed by microbiological methods.

2. The changes observed showed similar trends in both normal and cystinuric subjects.

3. Following ingestion of cystine only slight, possibly insignificant, changes in plasma cystine level were detected. There was no change in urinary cystine output.

4. Following ingestion of methionine there were only slight rises in plasma cystine levels but a slight increase in urinary cystine output occurred in the two cystinuric subjects. The plasma contained very high concentrations of methionine.

5. Following ingestion of cysteine there were very large rises in plasma cystine levels. Greatly increased urinary cystine outputs were also observed in both normal and cystinuric subjects.

6. The changes in output of cystine in the urine in any given subject roughly followed changes in plasma cystine level. In the two cystinuric patients, however, the urinary output was greatly increased over normal at all plasma levels.

7. These results are taken to support the suggestion of Dent and Rose (1) that in cystinuria the body tissues as a whole show no "error of metabolism" for cystine in the sense in which this term was used by Garrod. The biochemical findings in cystinuria can be better explained on the basis only of kidney tubule dysfunction.

8. Consistent slight changes occurred in the levels of $\alpha$-amino-n-butyric acid in some of these experiments, as if to suggest that it is closely related metabolically to the sulphur containing aminoacids (see also Dent and Schilling [7]).

\section{REFERENCES}

1. Dent, C. E., and Rose, G. A., Aminoacid metabolism in cystinuria. Quart. J. Med., 1951, 20, 205.

2. Fowler, D. I., Harris, H., and Warren, F. L., Plasmacystine levels in cystinuria. Lancet, 1952, (i), 544.

3. Brown, B. H., and Lewis, H. B., Cystine in normal and cystinuric human blood. Proc. Soc. Exper. Biol. \& Med., 1937, 36, 487.

4. Brand, E., Cahill, G. F., and Harris, M. M., Cystinuria. II. The metabolism of cystine, cysteine, methionine, and glutathione. J. Biol. Chem., 1935, 109, 69.

5. Dent, C. E., Applications to study of amino-acid and protein metabolism in Partition chromatography,
Biochem. Soc. Symposia No. 3., 1948, Cambridge University Press, 1951, p. 34.

6. Dent, C. E., Senior, B., and Walshe, J. M., The pathogenesis of cystinuria. II. Polarographic studies of the metabolism of sulphur-containing amino-acids. J. Clin. Invest., 1954, 33, 1216.

7. Dent, C. E., and Schilling, J. A., Studies on the absorption of proteins: the amino-acid pattern in the portal blood. Biochem. J., 1949, 44, 318.

8. Dent, C. E., Paper Chromatography and Medicine. Recent Advances in Clinical Pathology, 1951, ed. by S. C. Dyke, 2nd edn., London, Churchill, p. 238258.

9. Consden, R., Gordon, A. H., and Martin, A. J. P., The identification of lower peptides in complex mixtures. Biochem. J., 1947, 41, 590.

10. Dent, C. E., A study of the behaviour of some sixty amino-acids and other ninhydrin-reacting substances on phenol-'collidine' filter-paper chromatograms, with notes as to the occurrence of some of them in biological fluids. Biochem. J., 1948, 43, 169.

11. Dent, C. E., The amino-aciduria in Fanconi syndrome. A study making extensive use of techniques based on paper partition chromatography. Biochem. J., 1947, 41, 240.

12. Brand, E., Harris, M. M., and Biloon, S., Cystinuria. The excretion of a cystine complex which decomposes in the urine with the liberation of free cystine. J. Biol. Chem., 1930, 86, 315.

13. Riesen, W. H., Spengler, H. H., Robblee, A. R., Hankes, L. V., and Elvehjem, C. A., Cystine and related compounds in the nutrition of lactic acid bacteria. J. Biol. Chem., 1947, 171, 731.

14. Lyman, C. M., Moseley, O., Wood, S., and Hale; F., Note on the use of hydrogen peroxide-treated peptone in media for the microbiological determination of amino acids. Arch. Biochem., 1946, 10, 427.

15. Heathcote, J. G., The toxicity of small concentrations of cystine to acid-producing bacteria. J. Gen. Microbiol., 1949, 3, 392.

16. Camien, M. N., and Dunn, M. S., An improved microbiological method for the determination of cysstine in human urine with leuconostoc mesenteroides P-60. J. Biol. Chem., 1950, 183, 561.

17. Hier, S. W., Influence of ingestion of single amino acids on the blood level of free amino acids. J. Biol. Chem., 1947, 171, 813.

18. Garrod, A. E., Inborn Errors of Metabolism, 1923, 2nd Edn., London, Henry Frowde and Hodder \& Stoughton.

19. Hess, W. C., and Sullivan, M. X., Cystinuria. The effect of various amino acids on the excretion of cystine. J. Biol. Chem., 1942, 142, 3.

20. Freudenberg, E., Cystinosis: Cystine Disease (Lignac's Disease) in Children in Advances in Pediatrics, vol. 4, 1949, New York, Interscience, p. 265292. 